\title{
Wikipedia and the Humanities in Higher Education: Past Time to Renegotiate the Relationship
}

\author{
Thomas J. Haslam
}

\begin{abstract}
Since Wikipedia's founding in 2001, higher education has found it controversial as a teaching and learning resource. Many faculty members still ban students from using Wikipedia for their coursework. But a noticeable disparity exists between how academics in STEM (science, technology, engineering, \& mathematics) and those in the humanities understand and engage Wikipedia as a teaching and learning resource. Wikipedia, as the scholarly research shows, is a far more credible source than generally acknowledged; and as many educators in STEM, and particularly the natural sciences, have also shown, Wikipedia can be a vital part of the undergraduate and graduate curricula. This study reviews the scholarship on Wikipedia; examines how Wikipedia can have a vital role in humanities education, including that of preparing students to write better and to do scholarly research; and argues why Wikipedia should be part of the humanities curricula globally.
\end{abstract}

Index Terms - College writing, humanities, English studies, Wikipedia, curriculum reform.

\section{INTRODUCTION}

Since its founding in 2001, Wikipedia has generated controversy in higher education. Some institutions at the department, program, or course level have implemented policies discouraging or even forbidding student use of Wikipedia. Jeff Maehre [1], in 2009, offered a cogent exploration of how such bans impact the learning environment, discussing instances at various American institutions of higher education. In a comprehensive 2012 study of Wikipedia usage at Liverpool Hope University, UK, as the controversy is hardly confined to American academia, Charles Knight and Sam Pryke [2] found that 58\% of the instructors expressly tell the students not to use Wikipedia; and least $77 \%$ of the students reported that Wikipedia was banned by one or more of their instructors. Likewise in 2012, Lauren Westberg [3] called attention to an ongoing debate between students and professors at Purdue University, USA, over the value of Wikipedia. In 2013, based in the UK, Gemma Bayliss [4] offered a methodically researched study to explore why many faculty in higher education have a cautionary attitude towards Wikipedia. And this list could be considerably extended.

In response to the general and obviously ongoing controversy, in 2009 Cathy N. Davidson and David Theo Goldberg [5], both distinguished professors in the humanities and well-known in American academia, argued in The Future

Manuscript received November 2, 2015; revised January 19, 2016. This research supported by the College of Liberal Arts, Shantou University, project code STF 13002.

Thomas J. Haslam is with the College of Liberal Arts, Shantou University, China (e-mail: haslam@stu.edu.cn). of Learning Institutions in a Digital Age that: "To ban sources such as Wikipedia is to miss the importance of a collaborative, knowledge-making impulse in humans who are willing to contribute, correct, and collect information without remuneration: by definition, this is education." This vital position statement, however, might obscure the fact that the controversy over Wikipedia in higher education remains predominantly one-sided: the humanities and STEM (science, technology, engineering, \& mathematics), and particularly the natural sciences in STEM, seem to have two very different understandings of Wikipedia as a resource for teaching and learning.

In 2008, for example, one year before the apologia for Wikipedia by Davidson and Goldberg [5] cited above, the scholarly journal RNA Biology stipulated that accepted contributors should also submit a Wikipedia page summarizing their work [6]. The stipulation by RNA Biology, as the preeminent scientific journal Nature reported, is just one "subset of a broader project, the WikiProject Molecular and Cellular Biology, which has marshalled hundreds of scientists to improve the content of biology articles in Wikipedia," and involves further collaboration with the Wellcome Trust Sanger Institute, the Rfam Open Access Database (currently hosted by the European Molecular Biology Laboratory), and the Novartis Research Foundation [6]. We have - as I will discuss shortly — additional and similar ventures by the sciences which directly engage Wikipedia on some level. These ventures, which involve working scientists, academics, leading research institutions, scholarly journals, and foundations, are about contributing to and improving Wikipedia as a global educational resource not merely tolerating it, as Davidson and Goldberg [5] seem to call for.

In regard to the general controversy concerning Wikipedia a resource for teaching and learning, and from my experience as a humanities professor and writing instructor, I argue the following:

1) It is past time for us to renegotiate our relationship with Wikipedia.

2) Wikipedia can and should have a vital role in humanities higher education, including preparing students to write better and to do scholarly research.

To make this case, first I will discuss some of the salient differences between how the sciences and humanities seem to understand Wikipedia. Second, I will address for many humanities professors a key concern: the credibility of Wikipedia. Third, I will describe practical ways in which Wikipedia can be part of the undergraduate humanities curriculum. Fourth, and finally, I will argue why Wikipedia should be part of the humanities curricula globally. 


\section{UNDERSTANDING WIKIPEDIA: STEM VS. HUMANITIES}

We can sharpen the distinction I introduced earlier between how academics in STEM and those in humanities seem to understand Wikipedia simply by reviewing the published literature. In 2010, Andrew Wood and Kate Struthers [7], in their letter published in the journal Medical Teacher, discussed their analysis of Wikipedia articles on key topics related to medical conditions, finding that the "entries were generally informative, accurate, comprehensive and useful resources for medical education." Wood and Struthers [7] conclude: "We have identified Wikipedia as an informative and accurate source for Pathology education and believe that Wikipedia is potentially an important learning tool for students of the 'Net Generation'." In the same year, 2010, for an article published in the journal History Teacher, Cullen J. Chandler and Alison S. Gregory [8] asserted: "Perhaps from an academic standpoint, Wikipedia may not be completely useless." Apparently, the study of history is far more a life or death matter than the study of medicine, and so has more rigorous standards. Chandler and Gregory [8] did concede that "Wikipedia may have appropriate uses in the college classroom." But since they provided no evidence or evaluation standards, the reader must wonder as to how their judgments were determined.

We see the same pattern at work again. In 2008, John W. Huss III et al. [9] in their study "A Gene Wiki for Community Annotation of Gene Function" published in Plos Biology, offered a detailed and data-driven analysis of their efforts to improve Wikipedia's content. They designed stub entries on genes, "developed a computer program to generate gene stubs in automated fashion," tracked the revision histories of their efforts, the page rankings, and more [9]. Documenting that the "gene wiki effort has already had a substantial and growing impact on the Wikipedia community," Huss et al. [9] called for "further contributions from scientists around the world" to help create with Wikipedia "a robust, cross-referenced tool for students, educators, and researchers everywhere." No questions here about the academic value of Wikipedia, or about how to maximize it.

In almost ironic counterpoint to Huss et al. [9], in 2010, Elizabeth M. Nix [10], in her article "Wikipedia: How It Works and How It Can Work for You," published in History Teacher, provided no data whatsoever nor articulated any larger agenda. Nor did Nix [10] bother to explain in detail how the assignment parameters were defined - an assignment which seemed an inspired one-off, but perhaps one day worth repeating. Moreover, despite the article's grandiose title, Nix displayed little knowledge of the Wikipedia community or its editorial practices, or the characteristics of open content collaboration, or etc. In contrast to Huss et al. [9], Nix [10] offered the reader less a scholarly case study and more a personal account of her adventure in incorporating a Wikipedia assignment into her teaching evidently, we should share Nix's surprise that the assignment worked out well, and we should likewise be willing to undergo such an adventure.

Indeed, we should.

In their 2011 peer-reviewed article for the Journal of Medial Internet Research, James M. Heilman et al. [11] examined the "intricacies, strengths, and weaknesses of
Wikipedia as a source of health information." Finding that "Wikipedia has evolved into an important medical resource for the general public, students, and health care professionals," Heilman et al. [11] further recommended that that medical schools should "challenge their students not only to read Wikipedia's articles critically, but also to rewrite, discuss, critique, and improve them." In other words, contributing to Wikipedia should become an established part of the medical school curriculum. No ambiguity or half-measures here. This same general recommendation is reiterated in 2015 by Verena G. Herbert et al. [12], who argued in BMC Medical Education that Wikipedia should be included 'in medical curricula, since guiding students' use and evaluation of information resources is an important role of higher education;" and furthermore, doing so "is of utmost importance to establish information literacy, evidence-based practices, and lifelong learning habits among future physicians early on, hereby contributing to medical education of the highest quality."

\section{A. In STEM, Recognition of Wikipedia's Value}

Here, at least, for the sciences and medical studies, we are well beyond debating whether Wikipedia as a teaching and learning resource is "completely useless" or "may have appropriate uses in the college classroom" [8]; we likewise are well beyond treating faculty and student engagement with Wikipedia as an unsystematic, risky and daring, but potentially promising adventure [10]. The scholarly journal PLoS Computational Biology, to cite yet another example from the sciences, has an ongoing collaboration with Wikipedia, which the journal editors recognized as "the world's most widely used knowledge source" [13]. This collaboration meets strict standards for scholarly accuracy and general readability; and the contributions by PLoS Computational Biology members are tracked, categorized, and further analyzed for possible improvement [14]. Again, in evaluating Wikipedia as teaching and learning resource for higher education, data matters; or it should, and not just professional speculation or personal experience. For almost a decade now, academics and professional organizations in the sciences have been rigorously and systematically studying Wikipedia and improving its content to the benefit of all concerned: faculty, students, researchers, and the global public (see [6], [9], [11], and [12], to start). The humanities in regard to Wikipedia can boast of no such accomplishments, although the venture "Wiki Women: Bringing Women Into Wikipedia through Activism and Pedagogy," as described in 2015 by Jennifer C. Edwards [15], seems to me an outstanding start with sustainable potential. Overall, however, we have a noticeable disparity between how academics in STEM and those in humanities seem to both understand and engage Wikipedia as a teaching and learning resource: this disparity is not to the advantage of the humanities educators or their students.

\section{B. In the Humanities, Two Persistent Objections}

Many academics in the humanities seem to have two primary issues with Wikipedia: 1) its credibility; and 2) its perceived impact on student writing assignments. I will discuss the credibility issue next; and following that, how I 
teach the Wikipedia article as a writing assignment - a project I first undertook in 2006 as a Visiting Assistant Professor of English at Suffolk University's now defunct campus in Dakar, Senegal. But before proceeding, I would be remiss not to acknowledge on the humanities side of the equation the 2009 work of James P. Purdy [16], "When the Tenets of Composition Go Public: A Study of Writing in Wikipedia," published in College Composition and Communication; and the aforementioned 2009 study by Jeff Maehre [1], "What it means to ban Wikipedia: An exploration of the pedagogical principles at stake," published in College Teaching. Both Purdy [16] and Maehre [1] provided exemplary arguments for Wikipedia as a teaching and learning resource. The case for Wikipedia, it seems to me, has already largely been stated for the humanities, although I further it here. Scholarly argument notwithstanding, what we in the humanities lack are the large-scale systematic projects and studies which the sciences have been undertaking for now almost a decade. So to help us reach this level of engagement, I will now turn to Wikipedia and the credibility issue.

\section{WIKIPEDIA AND THE CREDIBILITY ISSUE}

Because anyone can potentially contribute or edit a Wikipedia article, many people understandably hold that Wikipedia cannot serve as an educational resource. But like the content in Wikipedia itself, this position must also submit to a reality test.

\section{A. Commonplace Misunderstandings}

First, as it seems many academics are still unaware, Wikipedia has defined criteria for what counts as a legitimate contribution, and these criteria are enforced strictly and proactively, sometimes zealously, by a vast volunteer community [17]. To give an overview, articles for Wikipedia must be written from a neutral point of view [18]; must be verifiable, citing reliable and credible sources [19]; must give due weight to differing viewpoints on a subject [18]; must not contain personal opinion, original research, or argumentation [20]; and finally, must respect intellectual property rights [19], [21].

Second, a Wikipedia article is an encyclopedia article: not a peer-reviewed scholarly essay or case study, nor even masquerading as one [20]. So the credibility test becomes how well does Wikipedia compare to other encyclopedias, and for that matter, other general reference works such as college textbooks. According to a 2005 report by Nature, in comparison to Encyclopedia Britannica, Wikipedia did quite well - in fact, about equivalent in general accuracy and reliability on articles examined [22]. Since the Nature study [22] in 2005, and because Wikipedia has become a popular resource for people seeking medical information, several peer-reviewed studies have examined Wikipedia articles on health and medical topics in comparison with professionally established or vetted resources.

\section{B. Scholarly Studies of Wikipedia's Credibility}

A peer-reviewed 2012 study published in Psychological Medicine found that "the quality of information on depression and schizophrenia on Wikipedia is generally as good as, or better than, that provided by centrally controlled websites, Encyclopaedia Britannica and a psychiatry textbook" [23]. A peer-reviewed 2013 study published in Seminars in Dialysis found that "Wikipedia is a comprehensive and fairly reliable medical resource for nephrology patients that is written at a college reading level" [24]. A peer-reviewed 2014 study by researchers at Institute of Pharmacology and Toxicology, Technische Universität München, Germany, and published in PLOS One [25] found that "that Wikipedia is an accurate and comprehensive source of drug-related information for undergraduate medical education." And several more studies with similar findings could be cited.

These critical assessments do impact Wikipedia's ongoing efforts at credibility, and for the better. The Wikimedia Foundation, the not-for-profit organization behind Wikipedia, tracks the published scholarship and reports on it in their Research Newsletter, which includes vigorous discussions as to how the Wikipedia community might engage what scholarly research has indicated as possible areas of improvement [26]. But in regard to credibility, Wikipedia's primary need, as always, is greater participation from qualified experts who will either contribute needed or improve existing articles, and cite trustworthy, verifiable sources when doing so.

From peer-reviewed studies to professional assessments, I cited earlier statements by academics in the science and medical studies [7], [11], [12] which recognize Wikipedia as a valuable teaching and learning resource, and have found its content on surveyed topics to have generally accurate, good quality information. Wikipedia also, as these and other educators acknowledge, needs continuing contribution by qualified experts. But outside of the humanities, at least, it seems we have a general consensus on the credibility of Wikipedia: a Wikipedia article should be critically evaluated as one information source among many: not pre-emptively dismissed as lacking value. (This position is also held by some educators in the humanities, including the majority of those cited here within). Overall, the scholarly peer-reviewed research on Wikipedia does not support banning Wikipedia, although this remains a shockingly common practice [2], [4]. On the contrary, as the research shows, many educators have found Wikipedia an imperfect but invaluable teaching and learning resource for undergraduate and even graduate education.

\section{Transitioning to the Humanities Curriculum}

As a humanities professor who teaches writing, literature, and cultural studies, it remains mysterious to me why academics of various stripes have deemed Wikipedia worthy of inclusion in the medical school curricula (as discussed in [11], [12] and elsewhere), but not acceptable for the humanities at the undergraduate level (as contested in [1], [16] and elsewhere). In the next two sections, I discuss in some detail how I incorporate Wikipedia into my undergraduate humanities classes; with some less detail, how other educators have long since been doing likewise; and, finally, in way of conclusion, what some further possibilities are for Wikipedia and the humanities in higher education. 


\section{WIKIPEDIA IN THE HUMANITIES CURRICULUM}

Much of the debate in concerns whether or not a Wikipedia article can be cited a valid source in a student paper. To answer this, perhaps we first need to answer the general question as to whether any encyclopedia article should be considered a valid source for a scholarly paper, even at the undergraduate level. Agreeing with the founder of Wikipedia, Jimmy Wales, I would argue no typically, an encyclopedia article does not count as a scholarly source [27]. But in terms of creating a valuable learning experience for undergraduate students in the humanities, I am not discussing the Wikipedia article as a source but as a writing assignment. As mentioned earlier, articles for Wikipedia must be written from a neutral point of view [18]; must be verifiable, citing reliable and credible sources [19]; must give due weight to differing viewpoints on a subject [18]; must not contain personal opinion, original research, or argumentation [20]; and finally, must respect intellectual property rights [19], [21]. In my experience teaching the Wiki article assignment, meeting these criteria offers undergraduate college students several valuable challenges.

\section{A. The Wiki Article Writing Assignment}

To start, in my experience teaching at the college level in the USA, Japan, Senegal, UAE, and China, many undergraduate student-writers too often lapse into either simply asserting personal opinions or treating one familiar source as authoritative and final. In either case, under the guise of "originality" or of "stating the truth," student-writers will affirm the status quo bias of their respective social positions, and generally reinforce what they already think they know or are comfortable with. The Wiki article assignment forces the student out of these familiar habits and into a more cognitively challenging effort at neutrality, fairness, and some measure of objectivity and impartiality. Furthermore, the student must meet the requirement of verifiability of finding and properly citing trustworthy, credible sources. The student must have sources, plural, and not a source and must critically account for each. Moreover, rather than using the sources as evidence to advance a thesis, the student must present in concise form the current state of verifiable knowledge on a subject. This brings with it the obvious qualifications that the current state will change: that knowledge is a social activity, subjected always to further correction, revision, and creation.

I structure the assignment as follows [28]. In choosing an article topic, the student must research existing Wikipedia content, and find "red links" acknowledged noteworthy topics which are missing articles; or, alternatively, "stub" articles in need of and flagged for further development [21]. If a student wishes to contribute an article not present as either a red link or stub, the student needs to review again Wikipedia's standards for notability and inclusion [21], and check for alternative spellings and possible related articles of the same proposed topic to ensure it does not already exist. Once the student has found a topic, the student begins looking for quality sources as the contributed content must be verifiable. The student begins drafting the article on our class implementation of Media Wiki the same Open Source Wiki platform used by Wikipedia [29]. (This enables the student to learn and use the same editing tools as Wikipedia). The article undergoes both peer- and instructor-review during the writing process. After we have some agreement that the article has meet the basic criteria as defined by Wikipedia, with strong emphasis on neutral point of view and no original research criteria, the student is encouraged to create an account at Wikipedia, check the article in the sandbox, and then if all looks good, contribute the article [21]. If a student wishes to use visual media in the article, our class requires that the visual media must already be in Wikimedia Commons; or, alternatively, the student can create media to be released under the appropriate Creative Commons license, and then uploaded to Wikimedia Commons.

Furthermore, when teaching the Wiki assignment, I also teach a sequence of concomitant lesson modules on copyright, citation methods, fair usage, the Creative Commons, and the Public Domain. The student cannot receive a passing grade for the assignment nor make a potentially viable contribution to Wikipedia if he or she has plagiarized or otherwise violated intellectual property rights. All this ties in neatly with and prepares the students for doing independent research in which they must properly use and cite sources, and must respect intellectual property rights. So the Wiki assignment, again, as I teach it is both a meaningful task in itself and helpful preparation for the more advanced writing assignments we also require of our students at Shantou University.

I first taught writing a Wiki article as a college writing assignment in 2006, at another university. Over the years, what I have found is this: in contrast to the typical essay assignment, the Wiki article is both a means and an end. It is a process which results in a product that endures beyond the course, has a potential global audience, and serves a real and relevant non-academic purpose (in addition to the academic one). Thus far, in my experience, the great majority of students have taken the Wiki article assignment seriously, devoting considerable effort to it; and should they choose to do so, showing pride when their article is finally posted at Wikipedia and survives (if it does) the gauntlet of senior Wikipedia editors who track new contributions and all but pounce on the same. But in nearly all cases to date of students who move from our course Media Wiki implementation to Wikipedia, the individual student contribution does pass review, and the student-writer has accomplished something which receives acknowledgement and reinforcement from outside the classroom (and indeed, outside of academia) [28]

In other words, from developing to completing the article, the student is effectively participating in a civil conversation with the greater globalized Wikipedia community: the student is well beyond simply submitting a class assignment to the instructor. I would also suggest that the Wiki article assignment contributes in a small way to our larger College of Liberal Arts goal at Shantou University of encouraging in our students a sense of global citizenship: active and meaningful engagement on issues of transnational importance; a critical and creative understanding of the same; and membership however virtual or tentative in global civil society. I note with great satisfaction that in 2008, Rachel Goodman [30] in The American Biology Teacher argued largely the same: that "students contribute to a global community through improvement of Wikipedia."

Moreover, and on the related issues of disparate global 
participation in digital culture and the digital divide, I note that my African students and Chinese students have contributed to the English Wikipedia articles on topics that many American users of Wikipedia, for example, might find of interest or value, but would likely not have the cultural knowledge or the initial interest to contribute. So I would strongly recommend the Wiki writing assignment for global speakers of English (aka, ESL/EFL students), and for international undergraduate English programs. Writing well which might take much effort and revision should be a requirement; being a native speaker of English is not.

So if a college instructor desires to teach his or her students about the limits and vulnerability of Wikipedia, and in addition wants the students to become more critical consumers of digital culture in general, one of the best things that instructor could do is have the students create and contribute articles in accordance with Wikipedia's criteria.

\section{B. Other Ventures with Wikipedia and the Humanities}

Outside of Edwards [15] "Wiki Women," my research has turned up no large-scale projects with clearly defined outcomes, nor even any smaller-scale projects in which data collection, analysis, and follow-up are integral components from the start. This clearly marks areas for improvement. Despite my sharp criticisms of the rhetoric and methods (or lack thereof) employed by Chandler and Gregory [8] and Nix [10], these educators are breaking relatively new ground in the humanities and their projects in general terms are certainly worthwhile and no doubt eye-opening to many. These projects mainly concern as my efforts do teaching on the undergraduate level. On the graduate level, Nicola Simmons [31] in 2013 described her project with having Masters candidates in Education contribute to Wikipedia, finding that the students "outlined significant learning as a result of this assignment." In other words, thus far, every educator in the humanities who has tried this and published on it has also reported that the Wikipedia project in question either met or exceeded expectations as a learning experience for both faculty and students alike. From the same [8], [10], [15], [31], and from other sources, interested educators in the humanities have the trails blazed for moving forward.

For faculty teaching on either level, undergraduate or graduate, I reiterate my recommendation of the outstanding arguments made by Purdy [16] and Maehre [1] for why we should consider integrating Wikipedia into the curriculum. For educators seeking both a succinct overview of Wikipedia and a how-to guide for getting started, I know of no better recent source than "Wicked or Wonderful: Revisiting Wikipedia," which Annette Lamb and Larry Johnson [32] published in Teacher Librarian for 2013. It is widely available, having been republished elsewhere; and Lamb [33] also has developed a companion online resource. Finally, Wikipedia itself has an Education Program, specifically designed to facilitate educational ventures [34]. This is a rapidly developing project, with new and improved content and resources being added on a regular basis. Although for educators new to Wikipedia, I would still recommend consulting first Lamb and Johnson [32], Wikipedia's own Education Program will likely soon prove the definitive resource for higher education faculty, students, and institutions alike [34].

\section{CONCLUSION}

Similar to the many other scholars and educators I have cited in this paper, I have discussed the considerable benefits of integrating Wikipedia into the curriculum, and particularly doing so by making standards-based contributions to Wikipedia as part of the general package of undergraduate writing assignments. I also strongly recommend keeping data on the same, and doing follow-up research on the submitted contributions. To offer just one data point, doing so has greatly help me improve both how I teach the assignment and the general quality of the end result. But beyond integrating Wikipedia into the writing curriculum at universities where I have taught, I wonder what else is possible? Because I am a humanities professor, and because academics in the sciences already have underway several large-scale ventures which are transforming Wikipedia for the better, I am calling for my fellow humanities professors to likewise think big: what can we do with an international educational resource used daily by millions of people?

Nearly every course in the humanities has matching content in Wikipedia which could be improved; and if by chance that content is not present, it could be added. I tell my students, only half-jokingly: "If it is not in Encyclopedia Britannica, blame the editors; if it is not in Wikipedia, blame yourself." So to my fellow educators in the humanities, let me say roughly the same: "If you see a Wikipedia article in your area of expertise which lacks good writing, accurate and up-to-date information, and credible scholarly sources, you know who to hold responsible." Many of our colleagues in STEM, and particularly those in the sciences, have long since taken this sense of responsibility and opportunity to heart: their efforts and those of their students are transforming Wikipedia to benefit of higher education globally, and to the benefit of the global public. We in the humanities might do well, in this instance, to learn from the sciences and benefit from the example of our colleagues as citizen-scholars without borders.

\section{ACKNOWLEDGMENT}

This paper was written with support from the College of Liberal Arts, Shantou University (STU), and the Global Digital Humanities platform at STU. The author benefitted considerably from his discussion of these issues with Associate Professor James McDougall, Director of the Global Digital Humanities platform; Dr. Terry Bodenhorn, Dean of the College of Liberal Arts, STU; and Associate Professor Shen Huayu, Chair of the Department of Foreign Languages and Literature, STU.

\section{REFERENCES}

[1] J. Maehre, "What it means to ban Wikipedia: An exploration of the pedagogical principles at stake," College Teaching, vol. 57, no. 4, pp. 229-236, Fall 2009.

[2] C. Knight and S. Pryke, "Wikipedia and the University, a case study," Teaching in Higher Education, vol. 17, no. 6, pp. 649-659, Dec. 2012

[3] L. Westberg. (2012). Purdue students, professors debate Wikipedia. Purdue [Online]. Avanent. 
http://www.purdueexponent.org/campus/article b4da3c51-7977-52a1 $-95 \mathrm{db}-\mathrm{c} 96 \mathrm{eafad} 7 \mathrm{~d} 71 . \mathrm{html}$

[4] G. Bayliss, "Exploring the cautionary attitude toward Wikipedia in higher education: Implications for higher education institutions," New Review of Academic Librarianship, vol. 19, pp. 36-57.

[5] C. N. Davidson and D. Goldberg, The Future of Learning Institutions in a Digital Age, Cambridge, MA: MIT Press, 2009.

[6] D. Butler, "Publish in Wikipedia or perish," Nature, News, Dec. 2008

[7] A. Wood and K. Struthers, "Pathology education, Wikipedia and the net generation," Medical Teacher, vol. 32, no. 7, p. 618, July 2010.

[8] C. Chandler and A. Gregory, "Sleeping with the enemy: Wikipedia in the college classroom," The History Teacher, vol. 43, no. 2, pp. 247-257, Feb. 2010

[9] J.W. Huss, C. Orozco, J. Goodale, C. Wu, S. Batalov, T. Vickers, F. Valafar, and A. Su, "A gene Wiki for community annotation of gene function," Plos Biology, vol. 6, no. 7, p. e175, July 2008.

[10] E. Nix, "Wikipedia: How it works and how it can work for you," The History Teacher, vol. 43, no. 2, pp. 259-264, Feb. 2010

[11] J. M. Heilman, E. Kemmann, M. Bonert et al., "Wikipedia: A key tool for global public health promotion," Journal of Medical Internet Research, vol. 13, no. 1, p. e14, Jan. 2011.

[12] V. Herbert, A. Frings, H. Rehatschek, G. Richard, and A. Leithner, "Wikipedia - Challenges and new horizons in enhancing medical education," BMC Medical Education, vol. 15, p. e32, Mar. 2015.

[13] S. J. Wodak, D. Mietchen, A. M. Collings, R. B. Russell, and P. E. Bourne, "Topic pages: PLoS computational biology meets Wikipedia," PLoS Comput Biol, vol. 8, no. 3, p. e1002446, Mar. 2012.

[14] Wikipedia. (2015). Wikipedia: WikiProject Computational Biology. [Online]. Available: https://en.wikipedia.org/wiki/Wikipedia:WikiProject_Computational _Biology

[15] J. Edwards, "Wiki women: Bringing women into Wikipedia through activism and pedagogy," The History Teacher, vol. 48, no. 3, pp. 409-436, May 2015.

[16] J. Purdy, "When the tenets of composition go public: A study of writing in Wikipedia," College Composition and Communication, vol. 61, no. 2, pp. w351-w373, Dec. 2009.

[17] D. Jemielniak, Common Knowledge? An Ethnography of Wikipedia, Stanford, CA: Stanford University Press, 2014

[18] Wikipedia. (2015). Wikipedia: Neutral Point of View. [Online]. Available: https://en.wikipedia.org/wiki/Wikipedia:Neutral_point_of_view

[19] Wikipedia. (2015). Wikipedia: Five Pillars. [Online]. Available: https://en.wikipedia.org/wiki/Wikipedia:Five pillars

[20] Wikipedia. (2015). Wikipedia: What Wikipedia Is Not. [Online]. Available:

http://en.wikipedia.org/wiki/Wikipedia:What_Wikipedia_is_not

[21] Wikipedia. (2015). Wikipedia: Your First Article. [Online]. Available: https://en.wikipedia.org/wiki/Wikipedia:Your_first_article

[22] J. Giles, "Special report: Internet encyclopaedias go head to head," Nature, vol. 438, pp. 900-901, Dec. 2005.

[23] N. J. Reavley, A. J. MacKinnon, A. J. Morgan, M. Alvarez-Jimenez, S. E. Hetrick, E. Killackey, B. Nelson, R. Purcell, M. B. H. Yap, and A. F. Jorm, "Quality of information sources about mental disorders: A comparison of Wikipedia with centrally controlled web and printed sources," Psychological Medicine, vol. 42, no. 8, pp. 1753-62, Aug. 2012.

[24] G. R. Thomas, L. Eng, J. F. D. Wolff, and S. C. Grover, "An evaluation of Wikipedia as a resource for patient education in nephrology," Seminars in Dialysis, vol. 26, no. 2, pp. 159-63, Apr. 2013.

[25] J. Kräenbring et al., "Accuracy and completeness of drug information in Wikipedia: A comparison with standard textbooks of pharmacology,” PLoS ONE, vol. 9, no. 9, p. e106930, Sept. 2014

[26] Wikimedia Foundation. (2015). Research Newsletter. [Online]. Available: https://meta.wikimedia.org/wiki/Research:Newsletter

[27] B. Helm. (2005). Wikipedia: 'A work in progress'. Bloomberg Business Week. [Online]. Available: http://www.businessweek.com/technology/content/dec2005/tc200512 14_441708.htm

[28] T. J. Haslam, "Global English, digital literacy, and the digital humanities: Defining the transition for an undergraduate writing program," presented at the Seventh International Conference on e-Learning and Innovative Pedagogies, Portland, OR, USA. Oct. 9 , 2014.

[29] Wikimedia Foundation. (2015). Welcome to MediaWiki.org. [Online] Available: https://www.mediawiki.org/wiki/MediaWiki

[30] R. Goodman, "Students contribute to a global community through improvement of Wikipedia," The American Biology Teacher, vol. 70 no. 3, p. 138 , Mar. 2008

[31] N. Simmons, "Inquiry, critique, and dissemination of knowledge: Graduate students contributing to Wikipedia," Collected Essays on Learning and Teaching, vol. VI, vol. 6, pp. 18-22, 2013.

[32] A. Lamb and L. Johnson, "Wikipedia: Wicked or wonderful?" Teacher Librarian, vol. 40, no. 4, pp. 68-73, Apr. 2013.

[33] A. Lamb. (2013). Wicked or Wonderful: Revisiting the World of Wikipedia. [Online]. Available: http://eduscapes.com/sessions/wikipedia/

[34] Wikimedia Foundation. (2015). Wikipedia Education Program. [Online]. Available: https://outreach.wikimedia.org/wiki/Education

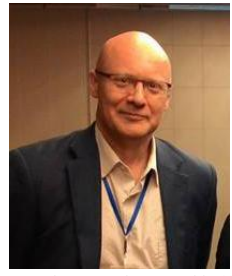

Thomas J. Haslam was born in Pennsylvania, USA He received a BA from St. Joseph's University, Philadelphia, PA, USA; and an MA and a PhD from the University of Delaware, Newark, DE, USA. He currently serves as a professor in the College of Liberal Arts, Shantou University, Guangdong, China. His previous international appointments include serving as the academic director and visiting associate professor for Suffolk University, Boston, MA, USA, at the Dakar campus in Dakar, Senegal, West Africa; as an assistant professor at Sharjah College, Sharjah, UAE; and as a Lecturer at the Faculty of Policy Studies, Chuo University, Hachioji-Shi, Japan. Outside of academia, he has been employed in web development and technical communication.

Professor Haslam has research interests in and has published on English studies, the digital humanities, cognitive literary studies (aka, the neurohumanities), and colonial/postcolonial studies. He is a founding member of the Global Digital Humanities platform at Shantou University, and a member of IEDRC. 